\title{
NUMERICAL ANALYSES OF OPENFOAM'S OVERTOPPING DEVICE SOLUTION
}

\author{
D. V. E. Barbosa ${ }^{a}$, \\ J. A. Souza ${ }^{a}$, \\ E. D. dos Santos ${ }^{a}$, \\ L. A. Isoldi ${ }^{\mathrm{a}}$, \\ and J. C. Martins ${ }^{\mathrm{b}}$ \\ ${ }^{\text {a }}$ Universidade Federal do Rio Grande \\ Escola de Engenharia \\ Italia Avenue, km 8, CP 474, \\ Rio Grande, Rio Grande do Sul, Brasil \\ dante_barbosa@yahoo.com.br

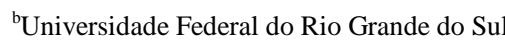 \\ Departamento de Engenharia Mecânica \\ Rau Sarmento Leite, 425, CEP 990050-170, \\ Porto Alegre, Rio Grande do Sul, Brasil
}

Received: May 11, 2017

Revised: June 12, 2017

Accepted: July 06, 2017
ABSTRACT

Studies related to ocean energy are getting more important lately, once world claims for renewable energy usage. The Overtopping Device is a kind of Ocean Waves Energy Converter (OWEC), which main concept is storing water provided by incident waves above sea level to feed a set of low head turbines. In order to obtain the desired effect, this device contains a ramp which elevates the incident waves toward the reservoir. Present study aims to perform a numerical model of a 2D Overtopping Device by means of OpenFOAM simulations. OpenFOAM is a free open source code which has shown applicability in many areas of engineering. The adopted solver (InterFOAM) is Volume of Fluid based (VOF) according to Finite Volume Method (FVM), these methodologies has been largely used among researchers in propagating waves field. FLUENT (commercial code) is used to verify OpenFOAM's results. Once, the main point of this paper is to present OpenFOAM as a considerable tool for propagating waves studies, it firstly presents a numerical wave verification with analytical solutions (second order Stokes theory). The second section of results presents overtopping time series peaks in $100 \mathrm{~s}$ of simulation. Also, by mass flow rate integration, it presents total mas of water climbed to the reservoir. The integration of mass flow rate takes $94 \mathrm{~s}$ of simulation (not $100 \mathrm{~s}$ ) because it is noticeable a pause between two peaks of overtopping at that time. Results show agreement between wave elevation and wave velocity profiles with straight convergence of periods between analytical and numerical waves. Most important differences are found near air/water interface, owed to faster air flow at that region. Generally OpenFOAM and FLUENT results are similar, with converged overtopping time series peaks and their magnitudes too. Similarly, the amount of water marked by both software are close with very similar trend lines.

Keywords: overtopping device, ocean waves energy converter, OpenFOAM, InterFOAM, volume of fluid

\section{NOMENCLATURE}

a elementary volume face, $\mathrm{m}$

calpha user defined parameter

g gravity vector, $\mathrm{m} / \mathrm{s}^{2}$

$h \quad$ water level, $\mathrm{m}$

$H \quad$ wave height, $\mathrm{m}$

H1 device's height, $m$

$\mathrm{Ht}$ channel's height

$k$ wave number, $1 / \mathrm{m}$

L1 device's length, $m$

$\mathrm{Lr} \quad$ reservoir's length, $\mathrm{m}$

Lt channel's length, $\mathrm{m}$

m mass, $\mathrm{kg}$

mass flow reate, $\mathrm{m}^{3} / \mathrm{s}$

$S \quad$ device's submersion, $\mathrm{m}$

$T \quad$ wave period, $\mathrm{s}$

$t \quad$ time, $\mathrm{s}$

$\boldsymbol{U}$ velocity vector, $\mathrm{m} / \mathrm{s}$

$u \quad$ velocity in $\mathrm{x}, \mathrm{m} / \mathrm{s}$

$\boldsymbol{U} \boldsymbol{r}$ relative velocity between fluids, $\mathrm{m} / \mathrm{s}$

$v \quad$ velocity, $\mathrm{m} / \mathrm{s}$

w velocity in $\mathrm{z}, \mathrm{m} / \mathrm{s}$

$x \quad$ horizontal coordinate, $\mathrm{m}$
$\begin{array}{ll}\boldsymbol{X} & \text { position vector, } \mathrm{m} \\ \boldsymbol{Z} & \text { vertical coordinate, } \mathrm{m}\end{array}$

\section{Greek symbols}

$\alpha \quad$ phase fraction

$\sigma \quad$ surface tension coefficient

$\kappa \quad$ interface curvature

$\lambda$ wave length, $\mathrm{m}$

$\rho \quad$ density, $\mathrm{kg} / \mathrm{m} 3$

$\mu \quad$ dynamic viscosity, Pa.s

$\omega \quad$ wave frequency, $1 / \mathrm{s}$

\section{INTRODUCTION}

Recent studies have shown that ocean energy capability is extremely huge, with estimated potential between 2 TW to 3 TW - approximately $1 / 5$ of current global energy demand (Pelc and Fujita, 2002). According Thorpe (1999), the current technology stage of Ocean Wave Energy Generators (OWECs, or only WECs) is able to supply $16 \%$ of world electrical energy demand. Therefore, scientific community and private investors have the duty of 
making this potential available for countries energy grids once people claim for efforts on renewable energy sources development. WECs have been focus of researches in many fields, by either numerical and experimental methods, in laboratory scale to full scale (www.wavedragon.net, September, 5, 2016; Tedd and Kofoed, 2009). However, none of these technologies are completely established yet.

As consequence of this scenario, there are more than 1000 different patented proposals for wave energy devices, and several ones have demonstrated the potential for commercially electricity generation (Falnes and Lovseth, 1991). Amid these, three mechanisms deserve be mentioned, the Oscillating Water Column (OWC), Buoyant Bodies and the Overtopping Device (IEA-RETD organization, 2012). Those are examples of well succeeded technologies that may be pictured with commercial names, like LIMPET 500 (OWC), Pelamis (Buoyant Body) and Wave Dragon (Overtopping Device) (www.emec.org.uk, September, 5, 2016). LIMPET 500 was the first commercial wave plant in the world, installed in the island of Islay, Scotland. Pelamis Wave Power is the first wave energy machine bought by a utility company, and the Wave Dragon, is the most developed overtopping technology, with similar potential of fossil fuel based plants. The overtopping device elevates incident waves above sea level toward a reservoir which contains a set of low head turbines. In order to accomplish this job, this device uses a ramp that forces the increase of incident waves crest, culminating in the wave break above it.

Another subject which is very supported by this text is the evolution of numerical techniques owed to the improvement of the entire computational area. Higuera, Lara, and Losada (2013) studied wave generation and wave absorption boundary conditions (BCs) on OpenFOAM, which is a free open source package for computational fluid dynamics (CFD), finding reliable wave generation and stability for coastal application. For that, it was necessary to implement those BCs. It features a piston-type wave maker BC, which allows comparisons with laboratory test replications. Furthermore, as sea states are random and three dimensional (3D), the study reveals capability of generating any frequency-direction wave spectrum in its components. The numerical technique used in his study is the Finite Volumes Method (FMV) (Versteeg and Malalasekera, 1999; Maliska, 2004), applying the Volume of Fluid (VOF) (Hirt and Nichols, 1981) to treat multiphase formulation (air and water). FVM is the discretization method that, in order to obtain the approximate partial differential equation, integrates it in the conservative form over finite control volumes and time-steps. VOF is a way of modeling multiphase systems by adding a conservation equation for a phase fraction $(\alpha)$ factor that quantifies the relative volumetric occupation of determined fluid inside each finite control volume.
The seek of product design improvement has promoted numerical analyses before manufacturing processes, once operating aspects may be previously observed. Accordingly, WECs design have been target of many studies in numerical field. Gomes, et al. (2012) studied and OWC in a 2D domain applying FVM and VOF. For that, the commercial software ANSYS FLUENT (Fluent), has been utilized to apply and solve governing equations. In order of generating numerical waves, Gomes compiles an User Defined BC which contains a wave profile velocity components in. This manner of generate numerical waves have shown accuracy, therefore, has been widely used amidst researchers. Teixeira et al. (2013) also studies the OWC, finding its optimal chamber geometry by crossing device's and turbine's operating behaviors. This study also presents a comparison between a Navier Stokes code based (Fluinco), with Fluent, showing good convergence of results. Yet, it is important to mention that Fluent simulation is performed applying MVF and VOF, with wave velocity profile components at wavemaker BC furthermore, Goulart (2014) and Martins et al. (2015) also apply these methodologies to obtain results about the Overtopping Device.

Goulart (2014) carried out a 2D overtopping device in real scale, his study proposes the optimization of the device's ramp by applying constrains and degrees of freedom. The applied optimization method constrains ramp area and uses the ratio of ramp height and ramp width as degrees of freedom to determine comparable ramp configurations. This method need a objective function to be accomplished, which in Goulart's case is the amount of water climbed to the reservoir in 100 s of simulation. In this context, Martins et al. (2015) applied the same optimization method with additional parameters carried out, like wave period and others ramp construction areas. It finds that minor construction areas provides overtopping peaks advances, and also greater magnitudes of mass flow rate toward reservoir, improving significantly the objective function. Naturally wave period increase offers the objective function as well, once it carries more energy with it.

The present study objective is analyses OpenFOAM's solution of an Overtopping Device, considering that OpenFOAM is a free code which has demonstrated to be a powerful tool in many areas of science, including ocean area. First, the numerical wave is compared with mathematical model. Secondly, OpenFOAM's overtopping characteristics are compared with FLUENT's (ANSYS, 2009). All simulations adopts FVM for spatial and temporal discretization, and VOF for interface air/water tracking.

\section{MATHEMATICAL AND NUMERICAL PROCEDURE}


Open Field Operation and Manipulation (OpenFOAM) is used for this studies numerical procedure. It is a free open source CFD toolbox written in $\mathrm{C}++$, develop using object oriented. Thus, its modular structure offers advantages to program new solvers. The solver used for laminar incompressible unsteady two-phase flow is interFOAM (OpenFOAM, 2011; Ramim, 2001), which is adopted to carry out this paper's results.

\section{InterFOAM}

InterFOAM is a solver for two-phase flows according to FVM and VOF. It solves threedimensional governing equations, which are, continuity, momentum, and interface capturing.

$$
\nabla \cdot U=0
$$

$$
\begin{gathered}
\frac{\partial \rho U}{\partial t}+\nabla \cdot(\rho U U)-\nabla \cdot(\mu \nabla U) \\
=-\nabla p^{\prime}-g \cdot X \nabla \rho+\nabla U \cdot \nabla \mu+\sigma \kappa \nabla \alpha \\
\frac{\partial \alpha}{\partial t}+\nabla \cdot U \alpha+\nabla \cdot U_{r} \alpha(1-\alpha)=0 \\
U_{r}=\min (\text { calpha }|U|, \text { max }|U|)
\end{gathered}
$$

$\boldsymbol{U}$ is velocity vector $(\mathrm{m} / \mathrm{s}) ; \rho$ is density $\left(\mathrm{kg} / \mathrm{m}^{3}\right)$; $p^{\prime}$ is pseudo-dynamic pressure $(\mathrm{Pa}) ; \mathbf{g}$ is gravity acceleration $\left(\mathrm{m} / \mathrm{s}^{2}\right) ; \boldsymbol{X}$ is the position vector $(\mathrm{m})$; $\sigma$ is surface tension coefficient; $\kappa$ is the curvature of the interface; $\mu$ is dynamic viscosity (Pa.s); $\alpha$ represents volume fraction of determined fluid; $\boldsymbol{U}_{\boldsymbol{r}} \alpha(1-\alpha)$ is called "compression flux", it takes nonzero values only at the interface. This term enhances interface sharpness, $\boldsymbol{U}_{\boldsymbol{r}}$ is a relative velocity among the fluids, it is calculated as Eq. 4, where calpha is a user defined factor (calpha=1, for this study). It is important to mention that fluids properties ( $\rho$ and $\mu$ ) are balanced by $\alpha$ inside the finite volumes,

$$
\begin{aligned}
& \rho=\alpha \rho_{1}+(1-\alpha) \rho_{2} \\
& \mu=\alpha \mu_{1}+(1-\alpha) \mu_{2}
\end{aligned}
$$

where subscripts 1 and 2 define one or other fluid comprehended by the model.

Considering spatial discretization, this study presents a refinement grid test considering wave elevation profile. Temporal discretization follows Courant Number constrain $(\mathrm{Co}=0.25)$, resulting in adaptive time-steps.
The algorithm used by OpenFOAM is called PIMPLE, as it mixes the traditional PISO and SIMPLE algorithms. Its structure is inherited from the original PISO, although it allows equations under relaxation to ensure the equations convergence at each time-step.

\section{Wave maker Boundary Condition}

Wave maker BC is set applying component velocities profiles ( $u$ and $w$ ) equations defined by Second Order Stokes Theory (Dean and Dalrymple, 1991) following:

where $u$ is $\mathbf{U}$ component in $x$ direction and $w$ is $\mathbf{U}$ component in $z$ direction. $H$ is wave height $(\mathrm{m}) ; k$ is wave number $(1 / \mathrm{m})$; $z$ points to axis $z$ position; $\sigma$ is wave frequency $(1 / \mathrm{s}) ; h$ is water level $(\mathrm{m}) ; x$ points to axis $x$ position and $t$ points to time (s).

\section{PROBLEM DESCRIPTION}

Present simulations treat about an onshore overtopping device fixed on a coastal structure (Fig. 1) It is important to recall that this paper main intention is to analyses OpenFOAM results in comparison with analytical solutions and Fluent's solutions, so that, geometric issues like, channel's dimensions, device's area, water level $(h)$, device's submersion (S), etc. are inspired by Goulart, M. M. (2014) Msc. thesis, which defines those parameters based on a real scale onshore Overtopping Device.

Figure 1 illustrates the numerical domain, which is a $327 \mathrm{~m}$ wave channel (Lt) with an Overtopping Device inside. It is $10 \mathrm{~m}$ depth $(h=10 \mathrm{~m})$ and the device is located five meters up the floor $(S=5 \mathrm{~m})$. Reservoir is positioned at water level $(h)$ and covers $20 \mathrm{~m}(L r)$. Tank's surfaces and device's surfaces are set as wall no-slip BC shown with continuous lines in Fig. 1. Left boundary wave-maker BC contains a second order wave velocity profile function, which describes a wave with following characteristics: $h / \lambda=$ $0.15, \lambda=65.4 \mathrm{~m}, H=1 \mathrm{~m}, T=7.5 \mathrm{~s}$. Total height is twenty meters $(H t=20 \mathrm{~m})$, and the tank is under atmospheric pressure (Patm, dashed lines in Fig. 1).

\section{Pressure Velocity Coupling}




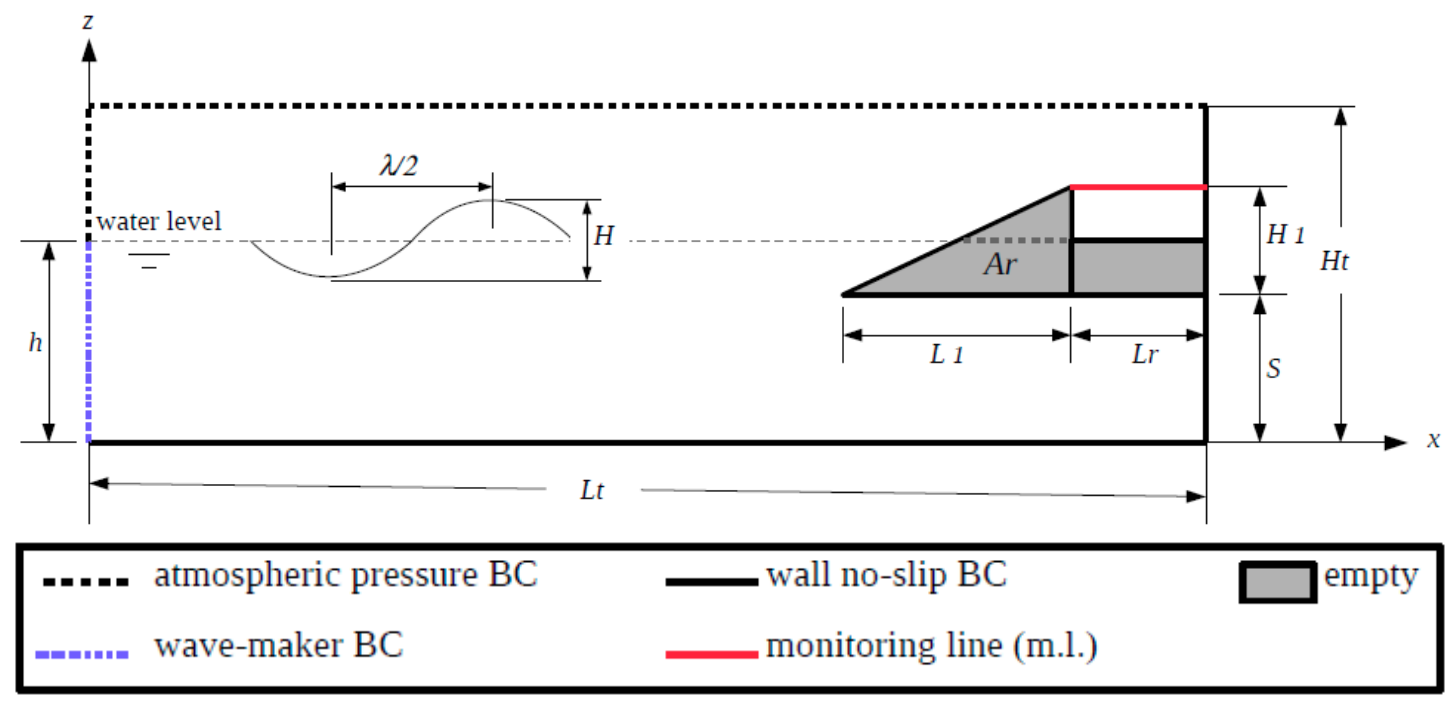

Figure 1. Generic domain and adopted boundary conditions.

Furthermore, seven different ramp geometries are carried out with $\mathrm{Ar}$ and $S$ constant. So, $\operatorname{Ar}\left(80 \mathrm{~m}^{2}\right)$ is maintained constant while $H_{1} / L_{1}$ gets following values $H_{1} / L_{1}=0.22,0.24,0.26,0.28,0.30,0.32$ and 0.34 (Goulart, M. M. 2014).

Figure 1 shows the monitoring line (m.l.) that covers the reservoir entrance. This is a schematic illustration of where mass flow rate $(\dot{m})$ is measured, its account occurs each time-step and is given by:

$$
\dot{m}=\sum_{i}^{n}(\alpha \rho w a)_{i}
$$

where $a$ is elementary volume faces covered by m.l..

Current section investigates free surface elevation and velocities profiles of the numerical wave by comparing results with analytical ones. Also, it presents a grid refinement test of concern to free surface elevation for OpenFOAM cases.

Regarding the Overtopping Device, it firstly shows the general mechanism of overtopping obtained with OpenFOAM simulations. After, it goes to results obtained with OpenFOAM and FLUENT, where overtopping time series and amount of water climbed to reservoir comparisons between the two software are shown.

\section{Refinement Grid Test and Numerical Wave}

Regarding to appropriate computational effort, the grid test is performed with consecutive refinements in $\Delta x$ volume dimensions, once $\Delta y$ are set according to bibliography recommendation $(\Delta y=$ $0.05 \mathrm{~m}$ ) (Gomes, 2012; Teixeira et al., 2013). Therefore, four grids with different dimensions for $\Delta x$ are presented (grid-1, grid-2, grid-3 and grid-4) in Tab 1. Those grids were generated with Gmsh (Geuzaine and Remacle, 2009) application, with tetrahedral volumes only.

Figure 2 shows the numerical free-surface prediction for each grid. The wave which intends to be modeled has $H=1 \mathrm{~m}$ (wave height), $\lambda=65.4 \mathrm{~m}$ (wave Length) and $T=7.5 \mathrm{~s}$ (wave period) (Based on Goulart, 2014). A time interval between 15 s and 35 $\mathrm{s}$, shows that free surface profile converges with grid refinements. Differences between grid-3 and grid-4 do not achieve $0.1 \%$, therefore grid-4 volumes dimensions were used for all presented simulation data. It is observed that wave trough is above $9.5 \mathrm{~m}$ and wave crest is above $10.5 \mathrm{~m}$, this illustrates nonlinear comportment according with second order Stokes waves.

Table 1. finite volumes dimensions for each grid.

\begin{tabular}{|c|c|}
\hline grid & $\Delta x-\Delta y(\mathrm{~m})$ \\
\hline 1 & $1.425-0.05$ \\
\hline 2 & $1.0-0.05$ \\
\hline 3 & $0.94-0.05$ \\
\hline 4 & $0.7-0.05$ \\
\hline
\end{tabular}

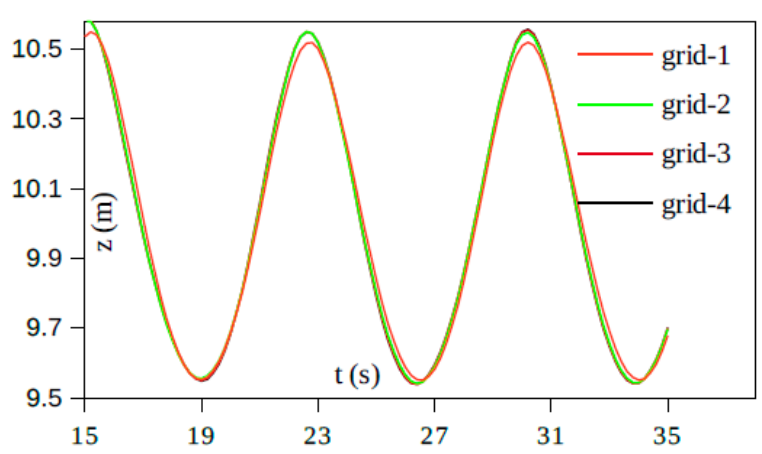

Figure 2. Results of grid refinement test.

Figure 3 compares the second order Stokes wave free surface elevation (analytical) with numerical wave obtained with grid-4 considering water level at $z=0 \mathrm{~m}$ (different than Fig. 2, which 
considers water level at $z=10 \mathrm{~m}$ in agreement with the domain shown in Fig 1). Most considerable differences achieve $10 \%$ at wave crests, what is compatible with numerical wave studies. Also, it is possible to visualize straight periods convergence between analytical and numerical waves.

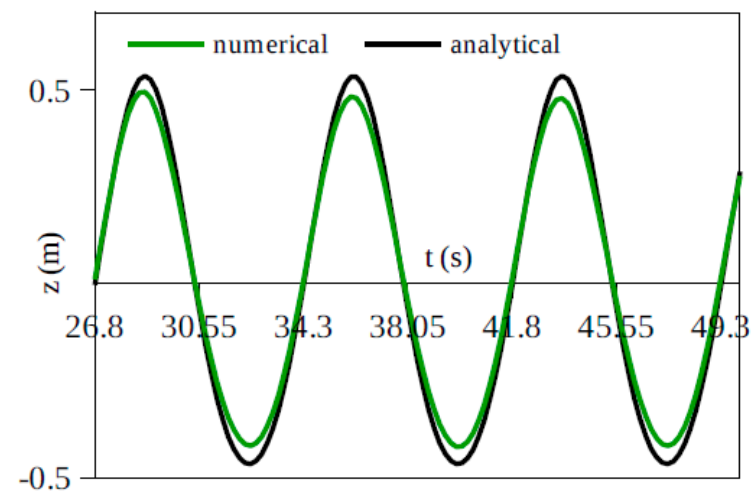

Figure 3. Numerical and Analytical free surface displacements.

Wave verification goes on with velocity profiles analyses under crest and trough. These profiles are compared with Stokes solutions in Fig. 4 and Fig. 5. Those figures plot $u$ and $w$ velocities in function of $z$ position along the two-dimensional wave channel.

Fig. 4 indicates that $w$ velocity under numeric wave crest ( $t=43.6 \mathrm{~s}$ ) is very close to the analytical one, with minor differences near from air/water interface $(z=0.5 \mathrm{~m})$, while, $u$ velocity presents $12 \%$ average difference between $z=-9.2 \mathrm{~m}$ and $\mathrm{z}=-0.5$ $\mathrm{m}$. It is noticeable that no-slip boundary conditions creates a discordance between model and analytical results, once it forces velocity to be $0 \mathrm{~m} / \mathrm{s}$ at $z=-10$ $\mathrm{m}$. It is also found a discordance at wave interface $(z$ $=0.5 \mathrm{~m}$ ), caused by faster air flow at that region. This air velocity at wave interface may also be responsible for differences found at analytical and numerical free-surface profile.

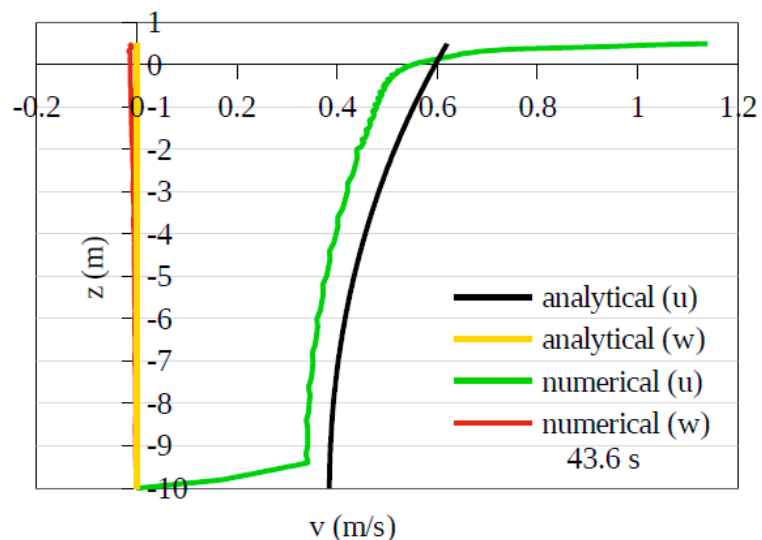

Figure 4. Wave velocity profile under a crest (t=43.6 s).

Fig 5 indicates that $\mathrm{w}$ velocity under the numeric wave trough ( $t=32.4 \mathrm{~s}$ ) is very close to analytical one, with minor differences near from air/water interface $(z=-0.5 \mathrm{~m})$, while, u velocity presents $12 \%$ average difference between $z=-9.2 \mathrm{~m}$ and $z=-1 \mathrm{~m}$. Once again no-slip boundary conditions creates discordances between numerical and mathematical models. It is found a disagreement at wave interface $(z=-0.5 \mathrm{~m})$, caused by faster air flow in positive direction again. In general, either above wave crest or trough, numerical velocities profiles in both directions have the right comportment, presenting magnitude differences around 12\%. Velocities profiles have major differences in $z=-10 \mathrm{~m}$ (because of no-slip BC) and interface air /water because of faster airflow occurrence.

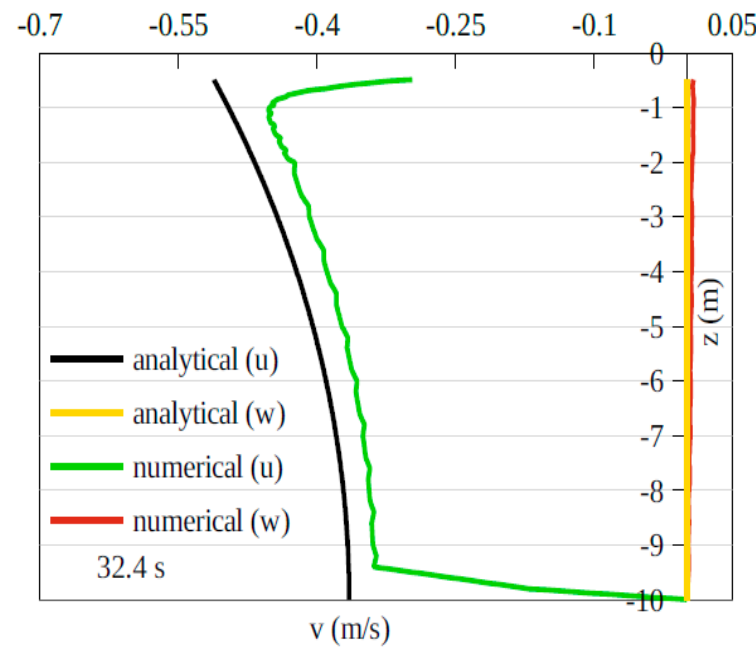

Figure 5. Wave velocity profile under a trough $(\mathrm{t}=32.4 \mathrm{~s})$.

\section{OVERTOPPING CHARACTERIZATION}

This section presents overtopping characteristics carried out with OpenFOAM and FLUENT simulations. Schematic domain (Fig. 1) receives $H_{1} / L_{1}=0.22,0.24,0.26,0.28,0.30,0.32$ and 0.34 , for a constant ramp area $\left(A r=80 \mathrm{~m}^{2}\right)$, and mass flow rate is measured through the monitoring line each time step simulation. So that, it is estimated total mass inside the reservoir after $94 \mathrm{~s}$ of simulation because there is a pause between two overtopping peaks at this time. Therefore, integration of mass flow rate considers six representative overtopping peaks. Figure 6 illustrates overtopping mechanism pictured of OpenFOAM simulation, it is possible to identify air $(\alpha=0)$ and water $(\alpha=1)$ phases been separated by a sharp interface in between, regarding calpha parameter equals to 1 . Incident wave crest increases by interaction with the device's ramp $\left(H_{1} / L_{1}\right.$ $=0.24$ ), causing the wave break followed by wave overtopping toward the reservoir. 

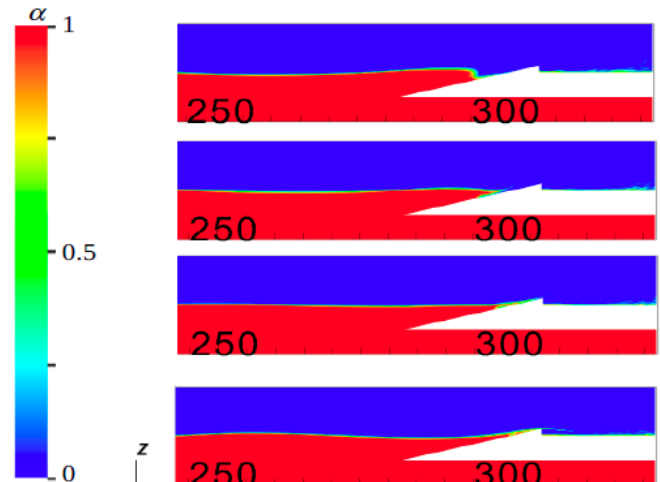

$88 \mathrm{~s}$



$89 \mathrm{~s}$

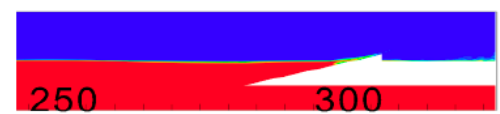

$90 \mathrm{~s}$

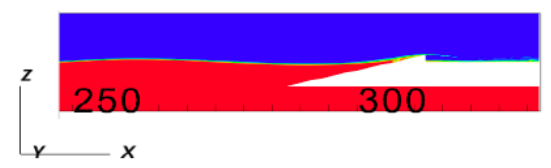

$91 \mathrm{~s}$

Figure 6. Overtopping process illustration depicted in OpenFOAM $(\mathrm{H} 1 / \mathrm{L} 1=0.24)$.

Figure 7 plots mass flow rate through the monitoring line for same ramp inclination $\left(H_{1} / L_{1}=0.24\right)$ measured with FLUENT and OpenFOAM simulations, using identical grids. Firstly, it is noticeable the simultaneity of overtopping time series between both piece of software. Although this is a good result, OpenFOAM measures seem to bee more instable, with fluctuations between overtopping peaks, what may be occasioned for interpolation functions particularities. It was observed that FLUENT presents similar fluctuations on mass flow rate measures depending on which interpolation function is set for advective therms, in general, advective high order schemes causes FLUENT's mass flow rate measures fluctuations too. However, none tries to eliminate OpenFOAM's fluctuations in response of advective schemes changing was successful. It points outs that interface tracking schemes may also be responsible for mentioned instability, once OpenFOAM adopts a compression flux to enhance sharpness between phases, while FLUENT uses an interface reconstruction algorithm. Also, these fluctuations can be occasioned due to Eq. (9) (written by user), which may accounts reverse air flow through the monitoring line if there is any nonzero value of $\alpha$ being counted by m.l.. FLUENT does not count mass flow rate with Eq. (9) though, it adopts an own method of mass flow rate measurement, what may avoid this occurrence.

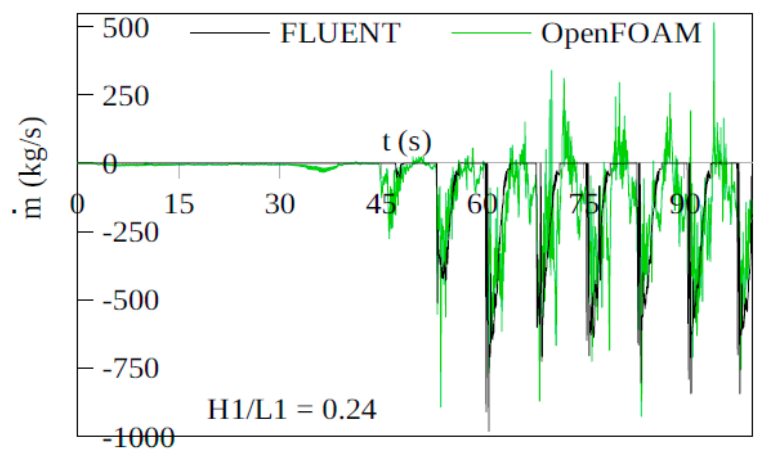

Figure 7. Overtopping time series, $H_{1} / L_{1}=0.24$.
With the exception of the first overtopping peak, between $45 \mathrm{~s}$ and $50 \mathrm{~s}$, not only time series peaks between both software converges, but also their magnitudes. Fig. 7 also highlights the overtopping pause at 94 s peak, what explains why mass flow rate integration considers a simulation time interval between $0 \mathrm{~s}$ to $94 \mathrm{~s}$. All seven geometries resulted in similar graphs, as example of Fig. 8, which illustrate same plots for $H_{1} / L_{1}=0.26$.

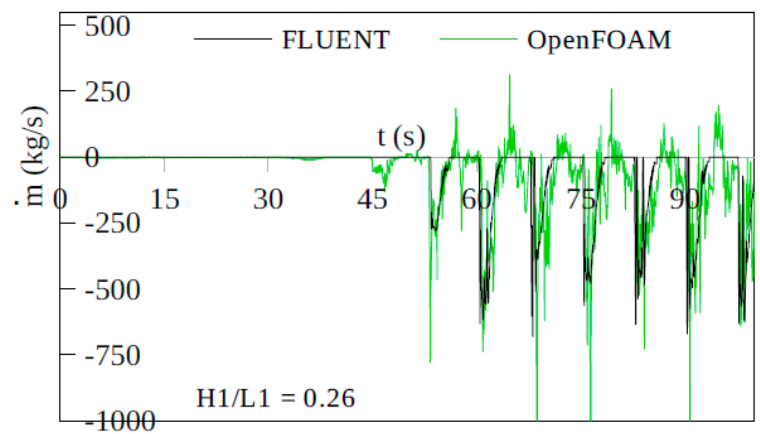

Figure 8. Overtopping time series, $H_{1} / L_{1}=0.26$.

Figure 9 shows total mass inside the reservoir of each studied ramp geometry. These results were obtained integrating mass flow rate. In agreement with Goulart (2014) checks that mass of water inside of the reservoir decreases when ramp's ratio $H_{1} / L_{1}$ increases. It is noticeable that trend lines of mass are similar between both software, what again show that OpenFOAM methodology fits to propagating waves studies area. Differences are found in $H_{1} / L_{1}=0.34$ where FLUENT does not present any water in the reservoir, but OpenFOAM predicts $877 \mathrm{~kg}$. That is because OpenFOAM always counts more mass or water than FLUENT (1258 kg average).



Figure 9. Mass of water inside the reservoir for each $H_{1} / L_{1}$.

As it is seen that results between software are similar, and OpenFOAM numerical waves characteristics agree with mathematical model. This study supports OpenFOAM usage to related studies, once it is a free code available for scientific 
community. Also, it must be mentioned that FLUENT is one of best FVM codes. Therefore this paper's does not point one software to be better than other one, but shows their general agreement at propagating waves modeling, applied to a coastal device.

\section{CONCLUSIONS}

Present study aims to present OpenFOAM as a considerable tool in wave propagating studies by modeling an Overtopping Device, which is a kind of Ocean Waves Energy Converter. First of all, mathematical equations are described, those are discretized according Finite Volume Method, by means of Volume of Fluid treatment for two-phase flow by means of InterFOAM solver. In order to verify results, this study also presents results of simulations performed with commercial code ANSYS FLUENT.

First results section brings a grid refinement test, which points a characteristic volume dimension capable of capturing air/water interface. It was seen that gird-4 wave elevation profile does not differs significantly from grid-3 wave profile. Therefore, grid-4 dimensions are indicated for OpenFOAM twodimensional propagating waves modeling. Fig 3 illustrates its good agreement between numerical free-surface displacement with analytical one, with acceptable difference of $10 \%$ at wave crest, and straight convergence of wave period. Also velocities profile between mathematical and numerical models are compared, showing general agreement. Although, it was observed that no-slip boundary condition at channel's floor creates a velocity gradient at the bottom, what is a model condition. However, model's limitation is owed to air flow near from air/water interface, which is faster than wave velocity, affecting velocity wave profile and, probably, freesurface profile as well. Overall results show that OpenFOAM is applicable for wave propagating waves studies, with agreement with analytical wave model (12\% average difference), and good agreement with bibliography results.

Subsequent results section treats about overtopping series characterization. It is shown wave crest elevation followed by wave break captured in OpenFOAM's simulation. Both phases are distinguishable and sharpness between phases are observed. Once water passes through the monitoring line positioned at reservoir entrance, its mass flow rate is took into account generating graphs like Figs. 7 and 8. These figures also plot measures obtained with FLUENT, where simultaneity of overtopping time series between both software simulations is noticeable. Also similar magnitudes of overtopping peaks are observed. Simulations were performed with seven ramp geometries, finding similar comportment presented in Figs. 7 and 8. By doing all studied geometries mass flow rate integrals, it was obtained the total mass climbed to the reservoir (Fig. 9), which again show similarities between FLUENT and OpenFOAM. OpenFOAM's measures present a systematic difference from FLUENT's, with higher values of water climbed to reservoir (average of 1258 $\mathrm{kg}$ ), although those trend lines are very similar. Also, these results agree with Goulart (2014), pointing total water increase by $H_{1} / L_{1}$ decrease, while the ramp area and ramp submersion $(S)$ is maintained constant.

Some modeling aspects have to be more deeply studied in the future, like the minimization of air velocity at air/water interface, and OpenFOAM's overtopping peaks fluctuations occurrence. Also, the future development of a turbulent model is important to observe differences from the laminar model. Despite of that, this paper's purpose succeed.

\section{REFERENCES}

ANSYS, 2009, ANSYS FLUENT 12 Theory Guide, Fluent Inc.

Geuzaine, C., and Remacle, J. F., 2009, Gmsh: a Three-Dimensional Finite Element Mesh Generator with Built-in Pre- and Post-Processing Facilities, International Journal for Numerical Methods in Engineering, Vol. 79 No. 11, pp. 1309-1331.

Falnes, J., and Lovseth, J., 1991, Ocean Wave Energy, Energy Policy.

Gomes, M. N., Nascimento, C. D., Bonafini, B. L., Santos, E. D., Isoldi, L. A., and Rocha, L. A. O., 2012, Otimização Geométrica 2D com Constructal Design de um Dispositivo do tipo Coluna de Água Oscilante em Escala de Laboratório, in: V Seminário e Workshop em Engenharia Oceânica, Rio Grande, RS. (in Portuguese)

Gomes, M. N., Santos, E. D., Isoldi, L. A., and Rocha, L. A. O, 2012, Análise de Malhas para Geração Numérica de Ondas em Tanques, in: VII Congresso Nacional de Engenharia Mecânica, São Luiz, MA. (in Portuguese)

Goulart, M. M., 2014, Estudo Numérico Da Geometria de um Dispositivo de Galgamente Onshore em Escala Real Empregando Constructal Design, Master Thesis, Universidade Federal do Rio Grande, Rio Grande, RS. (in Portuguese)

Higuera, P., Javier, L. L., and Inigo, J. L., 2013, Realistic Wave Generation and Active Wave Absorption for Navier-Stokes Models, Coastal Engineering, Vol. 71, pp. 102-118.

Hirt, C. W, and Nichols, B. D., 1981, Volume of Fluid (VOF) Method for the Dynamics of Free Boundaries, Journal of Computational Physics, Vol. 39, No. 1, pp. 201-225.

IEA-RETD (Organization), ed. 2012, Offshore Renewable Energy: Accelerating the Deployment of Offshore Wind, Tidal, and Wave Technologies, 1st Edition, Abingdon, Oxon, New York, NY: Earthscan.

Maliska, C. R., 2004, Transferência de Calor e Mecânica dos Fluidos Computacional, Rio de Janeiro: Livros Tecnicos e Cientificos. (in 


\section{Portuguese)}

Martins, J. C., Barbosa, D. V. E, Goulart, M. M., Rocha, L. A. O, Souza, J. A., Gomes, M. N., Isoldi, L. A., and Santos, E. D, 2015, Constructal Design of an Onshore Overtopping Device in Real Scale for Two Different Ocean Wave Periods and Different Areas of the Ramp, in: XXXVI Iberian Latin-American Congress on Computational Methods in Engineering 2015, Rio de Janeiro, Rio de Janeiro, Brazil.

OpenFOAM, 2011, OpenFOAM User’s Guide.

Ramim, P., Petit, O., and Nilsson, U, 2001, Project work: InterSettingFoam.

Pelc, R., and Fujita, R. M., 2002, Renewable Energy from the Ocean, Elsevier Science Ltd.

Dean, R. G., and Dalrymple R. A., 1991, Water Wave Mechanic for Engineers and Scientists, Vol. 2, Advanced Series on Ocean Engineering, World Scientific Co. Pte. Ltd.

Tedd, J., and Kofoed, J. P., 2009, Measurements of Overtopping Flow Time Series on the Wave Dragon, Wave Energy Converter, Renewable Energy, Vol. 34, No. 3, pp. 711-717.

Teixeira, P. R. F., Djavan P. D., Didier, E., and Ramalhais, R., 2013, Numerical Simulation of an Oscillating Water Column Device Using a Code Based on Navier-Stokes Equations, Energy, Vol. 61, pp. 513-530.

Thorpe, T. W., 1999, An Overview of Wave Energy Technologies: Status, Performance and Costs, in: 4th European Wave Energy Conference, Alborg, Denmark.

Versteeg, H. K., and Malalasekera, W., 1999, An Introduction to Computational Fluid Dynamics, malaysia: Longman. 